\title{
Determining spa-type of methicillin-resistant Staphylococcus aureus (MRSA) via High-Resolution Melting (HRM) analysis, Shiraz, Iran
}

\section{Zahra Hashemizadeh}

Shiraz University of Medical Sciences

Abdollah Bazargani

Shiraz University of Medical Sciences

\section{Samane Mohebi}

Shiraz University of Medical Sciences

Davood Kalantar-Neyestanaki

Kerman University of Medical Sciences

Nahal Hadi ( $\nabla$ hadina@sums.ac.ir)

\section{Research note}

Keywords: MRSA, HRM, Spa type

Posted Date: December 3rd, 2019

DOI: https://doi.org/10.21203/rs.2.17957/v1

License: (1) (i) This work is licensed under a Creative Commons Attribution 4.0 International License. Read Full License

Version of Record: A version of this preprint was published at BMC Research Notes on February 24th, 2020. See the published version at https://doi.org/10.1186/s13104-020-04948-z. 


\section{Abstract}

Objectives: Molecular typing methods are useful for rapid detection and control of a disease. Recently, the use of High-resolution melting (HRM) for spa typing of MRSA isolates were reported. This technique is rapid, inexpensive and simple for genotyping and mutation screening in DNA sequence. The aim of this study was to evaluate the ability of HRM-PCR to analysis spa genes amongst MRSA isolates.

Results: A total of 50 MRSA isolates were collected from two teaching hospitals in Shiraz, Iran. The isolates were confirmed as MRSA by susceptibility to Cefoxitin and detection of mecA gene using PCR. we used High-resolution melting (HRM) analysis and PCR-sequencing method for spa typing of MRSA isolates. In total, 15 different spa types were discriminate by HRM and sequencing method. The melting temperature of the 15 spa types, using HRM genotyping were between $82.16^{\circ} \mathrm{C}$ and $85.66^{\circ} \mathrm{C}$. The rate of $\mathrm{GC} \%$ content was 39.4-46.3. According to the results, spa typing of 50 clinical isolates via PCRsequencing and HRM methods were $100 \%$ similar. Consequently, HRM method can easily identify and rapidly differentiate alleles of spa genes. This method is faster, less laborious and more suitable for high sample at lower cost and risk of contamination.

\section{Introduction}

MRSA is one of the most common nosocomial pathogens worldwide, leading to severe morbidity and mortality. In Staphylococcus aureus, the mecA gene causes resistance to methicillin. This gene produces PBP2A (protein binding to penicillin) which inhibits beta-lactam antibiotics [1]. Molecular typing methods are useful for rapid identification and to control disease [2]. Nowadays, Pulsed-field gel electrophoresis (PFGE) is the gold standard method for the typing of $S$. aureus isolates; however, this method is time consuming process, expensive, complicated, and difficult to standardize [3]. Amongst molecular typing methods, SCCmectyping method is simple and cost effective with high discriminatory power to detect MRSA isolates associated with nosocomial infections [3]. In recent years, molecular typing of $S$. aureus has been performed by spa sequence typing [4]. The Staphylococcus protein A (spa) gene is the polymorphic $X$ region of protein $A$ in Staphylococcus, which determines the number of and sequence variation in repeats at the $X$ region of the spa gene $[5,6]$. In recent years, High-resolution melting (HRM) analysis has been used to analyze genetic variations. This technique is rapid, inexpensive, simple and cost effective for genotyping and mutation screening in DNA sequence [7]. HRM with real-time polymerase chain reaction (PCR) can be used for spa typing hypervariable $\mathrm{X}$ region of the spa gene [711]. In this technique, DNA strands are distinguished based on the length and percentage of the GC content [11]. The aim of this study was to assess the ability of HRM-PCR in analyzing spa genes amongst MRSA isolates.

\section{Materials And Methods}

\section{Bacterial isolates}


In this study, from January 2017 to June 2018, a total of 50 MRSA isolates were collected from different patients. After obtaining written informed consent from each participant, (number 96.15830). All isolates were identified as MRSA by standard biochemical tests, resistance to Cefoxitin and detection of mecA gene, as it was described previously[12].

\section{Spa typing}

The $X$ region of the spa gene was amplified, using spa-1113f (5-TAA AGA CGA TCC TTC GGT GAG C-3) and spa-1514r (5-CAG CAG TAGTGC CGT TTG CTT-3) primers[5]. The PCR assay contained the following components per reaction: $12.5 \mathrm{ml}$ Master mix (Amplicon, Denmark), $0.2 \mathrm{~mL}$ of each primer with concentration of $10 \mathrm{pmol} / \mathrm{mL}$ and $2 \mathrm{~mL}$ of DNA template top up to $25 \mathrm{~mL}$. PCR products were sequenced (Macrogen, Co, Korea) and assigned according to (http://www.spaserver.ridom.de).

\section{High-resolution melting PCR method}

The genomic DNA was extracted using Exgene Clinic SV (GeneALL, Seoul, Korea) according to manufacturer's guidelines and primer pair spa (spa-1113f and spa-1514r) were applied to the HRM method.

The HRM analysis was performed by the Quant studio real-time PCR system (ABI bio system, USA). HRM was performed in $25 \mu$ l-reaction containing $5 \mu$ l of 5 HOT FIREPol EvaGreen HRM Mix (ROX) (Solis BioDyne Co, Estonia), $1 \mu \mathrm{l}$ of each primer (10pM), $2 \mu$ l of DNA template $(20 \mathrm{ng})$ and $16 \mu$ l of water (DNase and RNase free water, SinaClon BioScience Co, Iran). The PCR thermocycling condition was: $95^{\circ} \mathrm{C}$ for 12 min, 40 cycles at $95^{\circ} \mathrm{C}$ for $15 \mathrm{~s}, 63^{\circ} \mathrm{C}$ for $20 \mathrm{~s}$ and $72^{\circ} \mathrm{C}$ for $20 \mathrm{~s}$. Then, $95^{\circ} \mathrm{C}$ for 1 min and $40^{\circ} \mathrm{C}$ for $1 \mathrm{~min}$ followed by HRM ramping from $75-90^{\circ} \mathrm{C}$ with fluorescence data acquisition at $0.5^{\circ} \mathrm{C}$ increments. The melting curves of all samples were analyzed by High Resolution Melt Software v3.0 (Thermo Fisher Scientific Co, USA).

\section{Results}

In the present study, total of 50 MRSA isolates were analyzed. Overall, 26 and 24 MRSA isolates were collected from female and male patients. The study group age range was between 8-90 years. The MRSA isolates were obtained from patient's skin $(19,38 \%)$, Blood $(10,20 \%)$, wound $(8,16 \%)$, Sputum $(5,10 \%)$, nasal $(5,10 \%)$, fluid $(1,2 \%)$, abases $(1,2 \%)$ and eye $(1,2 \%)$. Samples were isolated from different wards including Dermatology $(17,34 \%)$, Internal $(7,14 \%)$, Emergency $(7,14 \%), \operatorname{ICU}(6,12 \%)$ and outpatient $(12$, $24 \%)$.

Using conventional PCR-sequencing analysis for the 50 clinical isolates of MRSA, showed 15 different spa types, including spa types (t021, t018, t030, t037, t386, t081, t325, t345, t790, t314, t186, t304, t003, $\mathrm{t} 1877, \mathrm{t} 1816)$, and Spa type t030 was the major type in this study. These spa types were defined as the control for HRM analysis. HRM was designed for MRSA spa types. The processing time for HRM analysis was around $2 \mathrm{~h}$. The melting temperature of the $15 \mathrm{HRM}$ genotypes laid between $82.16^{\circ} \mathrm{C}$ and $85.66^{\circ} \mathrm{C}$. 
The rate of GC\% lies between 39.4 and 46.3 (Table1). Typing of the 50 clinical isolates by the PCRsequencing method and HRM method resulted in $100 \%$ similarity (Table1). By comparing the melting temperature, using known spa types we can determine other spa types.

Table1: Spa typing results of the 50 MRSA clinical isolates, using conventional PCR-sequencing method and HRM

\begin{tabular}{|c|c|c|c|c|c|}
\hline $\begin{array}{l}\text { Spa } \\
\text { types }\end{array}$ & $\begin{array}{l}\text { No. of } \\
\text { isolates(n:50) }\end{array}$ & PCR base spa types & $\begin{array}{l}\operatorname{Tm}\left({ }^{\circ}\right. \\
\mathrm{C})\end{array}$ & GC\% & $\begin{array}{l}\text { Size } \\
\text { bp }\end{array}$ \\
\hline t030 & 7 & $15-12-16-02-24-24$ & 83.83 & 44 & 250 \\
\hline t 037 & 2 & $15-12-16-02-25-17-24$ & 82.16 & 44.6 & 360 \\
\hline t 021 & 5 & $15-12-16-02-16-02-25-17-24$ & 85.3 & 43.9 & 300 \\
\hline t 386 & 4 & $07-23-13$ & 82.96 & 42.2 & 210 \\
\hline t 325 & 2 & 07-12-21-17-34-13-34-34-33-34 & 82.95 & 41.1 & 400 \\
\hline t 345 & 1 & $26-23-13-21-17-34-34-33-34$ & 85.18 & 41.7 & 350 \\
\hline t 790 & 1 & $\begin{array}{l}26-23-13-23-31-29-17-25-17-25-16- \\
28\end{array}$ & 84.13 & 44.1 & 450 \\
\hline t 314 & 1 & 08-17-23-18-17 & 85.66 & 44.6 & 270 \\
\hline t 186 & 1 & 07-12-21-17-13-13-34-34-33-34 & 84.5 & 41.8 & 300 \\
\hline t 304 & 1 & $11-10-21-17-34-24-34-22-25$ & 84.35 & 42.8 & 300 \\
\hline t 003 & 1 & $26-17-20-17-12-17-17-16$ & 85.33 & 44.4 & 280 \\
\hline t 1877 & 3 & $07-23-12-34-12-12-23$ & 84.38 & 44.4 & 290 \\
\hline t 1816 & 1 & $07-12-21-17-34-13-34-34-34-33-34$ & 84.57 & 39.4 & 400 \\
\hline t 018 & 1 & $15-12-16-02-16-02-25-17-24-24-24$ & 85.1 & 44.8 & 264 \\
\hline t 081 & 1 & $04-21-12-41-20-17-12-17$ & 85.3 & 46.3 & 192 \\
\hline
\end{tabular}

\section{Discussion}


MRSA can cause infections both in hospitals as well as communities [13, 14]. Due to outbreaks of MRSA increase in the mentioned settings, typing methods are vital to systematically control these infections. Molecular typing methods of microbial pathogens are important tools for detecting the outbreaks, controlling and preventing infections as well as for the epidemiological surveillance [5]. Different typing methods are done for epidemiological investigations such as PFGE, Multilocus sequence typing (MLST) , spa typing and SCCmectyping[14]. PFGE and MLST are appropriate typing methods; however, these methods are expensive and time-consuming[15]. Spa typing method is based on short sequence repeats of hypervariable $\mathrm{X}$ region in the spa gene, but this method is still expensive. But then again this typing method is effective and easy technique to detect typing MRSA isolates[16]. In a previous study, we found 15 different spa-types, and spa type t030 was the most common amongst MRSAs[17]. HRM analysis has been recently introduced as an appropriate method for epidemiological investigations and detection of sequence variants in clinical research and diagnostics. HRM method can easily and rapidly identify the different alleles of spa genes [11]. This method is used in a closed system and in the same tube as the amplification step; hence, it is faster, easier, and more suitable for high sample, which reduces the risk of contamination [18]. In our study, the results of HRM showed 15 different spa types. All of the isolates had significant difference in $\mathrm{Tm}$ and $\mathrm{GC}$ content. The $\mathrm{G}+\mathrm{C}$ percentage and the length of the tandem repeats in the Protein A region might cause differences in melting temperature among the samples. Our spa typing results was completely similar to HRM results. This finding is in line with the findings of Hon-Kwan Chen et al. study in China [8]. However, our results were in contrast with the results of Fasihi et al. [11] and Stephens et al. [10] , which showed that for some isolates, TM HRM with conventional PCR sequencing were different. HRM is a suitable method to be used to examine hypervariable loci, since it can provide more clearance for genotyping and diversity among MRSA strains. Also, another study claimed that this technique is less expensive than spa sequencing [19]. Spa typing using other typing methods, such as MLST and SCCmec and HRM can be distinguished better amongst MRSA clones in hospital [19]. Different values of melting temperature were reported for one spa type. HRM method can be affected by testing conditions and type of real time machine as well as HRM software $[9,11]$. In this study, Tm value for t030 was $83.83^{\circ} \mathrm{C}$, but in a previous study by fasihi et al. it was $85.3^{\circ} \mathrm{C}$. Also, in the present study as well as a previous study by Fasihi et al. HOT FIREPol EvaGreen HRM Mix (ROX) was used, but in another study Platinum SYBRGreen was used [9]. In our study, using HRM technique, we used Quant studio realtime PCR system (ABI bio system, USA) and 5x HOT FIREPOL EvaGreen HRM Mix (ROX) (Solis Bio Dyne Co, Estonia) while in another study, a different real time machine and master mix was used $[8,9]$. These differences can be as result of using different real time PCR device or Master Mix producing different TMs for the same spa type. Even though HRM method is simple, and more economical than the conventional method, it has several limitations. In this technique it is essential to have a known control type; however, if there is a new spa type conventional PCR-sequencing is required. Also, isolates that have the same GC content with the same TM, their discrimination is difficult[8].

\section{Conclusions}


HRM method is simple, more economical than the conventional method. HRM method can easily and rapidly identify the different alleles of spa genes. This method can analysis faster is less laborious, more suitable for high quantity samples with lowers risk of contamination. Accordingly, this technique has the potential to show variation, but require control, and should be accompanied by the spa gene sequence, and it is not suitable for new strains.

\section{Limitations}

A limitation in this study was that we did not carry out HRM for MSSA isolates, due to financial constraints.

\section{Abbreviations}

Methicillin-resistant S. aureus: MRSA, High-resolution melting :HRM, Staphylococcal cassette chromosome mec: SCCmec, PBP2A (protein binding to penicillin multilocus sequence typing :MLST, Pulsed field gel electrophoresis: PFGE, Clinical and Laboratory Standard Institute : CLSI

\section{Declarations}

\section{Acknowledgment}

The authors would like to thank Vice-chancellor of Research and technology of Shiraz University of Medical Sciences for the financial support (96.15830). The authors wish to thank Mr. H. Argasi at the Research Consultation Center (RCC) of Shiraz University of Medical Sciences for his invaluable assistance in editing this manuscript.

\section{Funding}

Research and technology of Shiraz University of Medical Sciences for the financial support (96.15830).

\section{Availability of data and materials}

The data that support the findings of this study are available. Anyone interested can get upon reasonable request from corresponding author.

\section{Authors' contributions}

$\mathrm{ZH}, \mathrm{SM}$ : conceived the study. ZH, SM, AB, NH, DK: participated in the design of the study and performed the statistical analysis. ZH, SM: interpreted the data. $\mathrm{ZH}, \mathrm{SM}$ : obtained ethical clearance and permission for study $\mathrm{ZH}, \mathrm{SM}$ : Supervised data collectors. . ZH, SM, AB, NH, DK: Drafting the article or revisiting it critically for important intellectual content. $\mathrm{AB}, \mathrm{NH}, \mathrm{ZH}$ : were project leaders and primary investigators of the study. All authors read and approved the final manuscript. 


\section{Ethics approval and consent to participate}

Not applicable.

\section{Consent for publication}

Not applicable.

\section{Competing interests}

The authors declare that they have no competing interests.

\section{Author details}

1 Department of Bacteriology and Virology, School of Medicine, Shiraz University of Medical Sciences, Shiraz, Iran.

2 Departments of Microbiology and Virology, School of Medicine, Kerman University of Medical Sciences, Iran

\section{References}

1. Boswihi SS, Udo EE. Methicillin-resistant Staphylococcus aureus: An update on the epidemiology, treatment options and infection control. Cutis. 2018;8(1):18-24. https://doi.org/10.1016/j.cmrp.2018.01.001

2. Mongelli G, Bongiorno D, Agosta M, Benvenuto S, Stefani S, Campanile F. High Resolution MeltingTyping (HRMT) of methicillin-resistant Staphylococcus aureus (MRSA): The new frontier to replace multi-locus sequence typing (MLST) for epidemiological surveillance studies. J Microbiol Methods. 2015;117:136-8. http://dx.doi.org/10.1016/j.mimet.2015.08.001

3. Darban-Sarokhalil D, Khoramrooz SS, Marashifard M, Hosseini SAAM, Parhizgari N, Yazdanpanah M, et al. Molecular characterization of Staphylococcus aureus isolates from southwest of Iran using spa and SCCmec typing methods. Microb Pathog. 2016;98:88-92. http://dx.doi.org/10.1016/j.micpath.2016.07.003

4. Strommenger B, Braulke C, Heuck D, Schmidt C, Pasemann B, Nübel U, et al. spa typing of Staphylococcus aureus as a frontline tool in epidemiological typing. J Clin Microbiol. 2008;46(2):574-81.http:// doi:10.1128/JCM.01599-07

5. Fasihi Y, Kiaei S, Kalantar-Neyestanaki D. Characterization of SCCmec and spa types of methicillinresistant Staphylococcus aureus isolates from health-care and community-acquired infections in Kerman, Iran. J Epidemiol Glob Health.. 2017;7(4):263-7.

http://dx.doi.org/10.1016/j.jegh.2017.08.004 
6. Votintseva AA, Fung R, Miller RR, Knox K, Godwin H, Wyllie DH, et al. Prevalence of Staphylococcus aureus protein $\mathrm{A}$ (spa) mutants in the community and hospitals in Oxfordshire. BMC Microbiol. 2014;14(63): 1-11. htpp://doi:10.1186/1471-2180-14-63

7. Tong S, Lilliebridge R, Holt D, McDonald M, Currie B, Giffard P. High-resolution melting analysis of the spa locus reveals significant diversity within sequence type 93 methicillin-resistant Staphylococcus aureus from northern Australia. Clin Microbiol Infect.. 2009;15(12):1126-31.http:// doi10.1111/j.1469-0691.2009.02732.x

8. Chen JH-K, Cheng VC-C, Chan JF-W, She KK-K, Yan M-K, Yau MC-Y, et al. The use of high-resolution melting analysis for rapid spa typing on methicillin-resistant Staphylococcus aureus clinical isolates. J Microbiol Methods. 2013;92(2):99-102. http://dx.doi.org/10.1016/j.mimet.2012.11.006

9. Mazi W, Sangal V, Sandstrom G, Saeed A, Yu J. Evaluation of spa-typing of methicillin-resistant Staphylococcus aureus using high-resolution melting analysis. Int J Infect Dis. 2015;38:125-8. http://dx.doi.org/10.1016/j.ijid.2015.05.002

10. Stephens AJ, Inman-Bamber J, Giffard PM, Huygens F. High-resolution melting analysis of the spa repeat region of Staphylococcus aureus. Clin Chem. 2008;54(2):432-6.http:// DOI:

10.1373/clinchem.2007.093658

11. Fasihi Y, Fooladi S, Mohammadi MA, Emaneini M, Kalantar-Neyestanaki D. The spa typing of methicillin-resistant Staphylococcus aureus isolates by High Resolution Melting (HRM) analysis. $J$ Med Microbiol. 2017;66(9):1335-7.http:// DOI 10.1099/jmm.0.000574

12. Wayne P. Clinical and Laboratory Standards Institute (CLSI). Performance standards for antimicrobial susceptibility testing. Twenty Second Inf Suppl. 2018;32(3):1-278.

13. Yan X, Song Y, Yu X, Tao X, Yan J, Luo F, et al. Factors associated with Staphylococcus aureus nasal carriage among healthy people in Northern China. Clin Microbiol Infect.. 2015;21(2):157-62. http://dx.doi.org/10.1016/j.cmi.2014.08.023

14. Mediavilla JR, Chen L, Mathema B, Kreiswirth BN. Global epidemiology of community-associated methicillin resistant Staphylococcus aureus (CA-MRSA). Curr Opin Microbiol.. 2012;15(5):588-95. http://dx.doi.org/10.1016/j.mib.2012.08.003

15. Faria NA, Carrico JA, Oliveira DC, Ramirez M, de Lencastre H. Analysis of typing methods for epidemiological surveillance of both methicillin-resistant and methicillin-susceptible Staphylococcus aureus strains. J Clin Microbiol. 2008;46(1):136-44.http:// doi:10.1128/JCM.01684-07

16. Harmsen $D$, Claus $H$, Witte $W$, Rothgänger $J$, Claus $H$, Turnwald $D$, et al. Typing of methicillin-resistant Staphylococcus aureus in a university hospital setting by using novel software for spa repeat determination and database management. J Clin Microbio.. 2003;41(12):5442-8.http:// DOI: 10.1128/JCM.41.12.5442-5448.2003

17. Hashemizadeh Z, Hadi N, Mohebi S, Kalantar-Neyestanaki D, Bazargani A. Characterization of SCCmec, spa types and Multi Drug Resistant of methicillin-resistant Staphylococcus aureus isolates among inpatients and outpatients in a referral hospital in Shiraz, Iran. BMC Res Notes.. 2019;12(614):1-6. https://doi.org/10.1186/s13104-019-4627-z 
18. Druml B, Cichna-Markl M. High resolution melting (HRM) analysis of DNA-Its role and potential in food analysis. FoodChem . 2014;158:245-54. http://dx.doi.org/10.1016/j.foodchem.2014.02.111

19. Tong SY, Lilliebridge RA, Holt DC, Coombs GW, Currie BJ, Giffard PM. Rapid detection of H and R Panton-Valentine leukocidin isoforms in Staphylococcus aureus by high-resolution melting analysis. Diagn Microbiol Infect Dis. 2010;67(4):399-401. http://doi:10.1016/j.diagmicrobio.2010.03.015

\section{Tables}

Table1: Spa typing results of the 50 MRSA clinical isolates, using conventional PCR-sequencing method and HRM

\begin{tabular}{|c|c|c|c|c|c|}
\hline Spa types & No. of isolates(n:50) & PCR base spa types & Tm( ${ }^{\circ}$ C) & GC\% & Size bp \\
\hline t030 & 7 & $15-12-16-02-24-24$ & 83.83 & 44 & 250 \\
\hline t 037 & 2 & $15-12-16-02-25-17-24$ & 82.16 & 44.6 & 360 \\
\hline t 021 & 5 & $15-12-16-02-16-02-25-17-24$ & 85.3 & 43.9 & 300 \\
\hline t 386 & 4 & $07-23-13$ & 82.96 & 42.2 & 210 \\
\hline t 325 & 2 & $07-12-21-17-34-13-34-34-33-34$ & 82.95 & 41.1 & 400 \\
\hline t 345 & 1 & $26-23-13-21-17-34-34-33-34$ & 85.18 & 41.7 & 350 \\
\hline t 790 & 1 & $26-23-13-23-31-29-17-25-17-25-16-28$ & 84.13 & 44.1 & 450 \\
\hline t 314 & 1 & $08-17-23-18-17$ & 85.66 & 44.6 & 270 \\
\hline t 186 & 1 & $07-12-21-17-13-13-34-34-33-34$ & 84.5 & 41.8 & 300 \\
\hline t 304 & 1 & $11-10-21-17-34-24-34-22-25$ & 84.35 & 42.8 & 300 \\
\hline t 003 & 1 & $26-17-20-17-12-17-17-16$ & 85.33 & 44.4 & 280 \\
\hline t 1877 & 3 & $07-23-12-34-12-12-23$ & 84.38 & 44.4 & 290 \\
\hline t 1816 & 1 & $07-12-21-17-34-13-34-34-34-33-34$ & 84.57 & 39.4 & 400 \\
\hline t 018 & 1 & $15-12-16-02-16-02-25-17-24-24-24$ & 85.1 & 44.8 & 264 \\
\hline t 081 & 1 & $04-21-12-41-20-17-12-17$ & 85.3 & 46.3 & 192 \\
\hline
\end{tabular}

